\title{
Resolution of Time Space Conflicts in Construction
}

\author{
Mohammad Ovais ${ }^{1}$ \\ Civil Engineering Department \\ AFSET, Al-Falah University \\ Haryana, India
}

\author{
Masoom Reza ${ }^{2}$ \\ Civil Engineering Department \\ AFSET, Al-Falah University \\ Haryana, India
}

\begin{abstract}
Work Space on construction sites is a crucial resource as other resources depend on it. Work space planning for various construction activities is of utmost importance especially when safety and productivity at construction sites have to be enhanced. Work space planning involves identifying various types of spaces needed for different construction activities in four dimension (4D) i.e. three dimensions along with time. The generation of these work spaces leads to a spaceloaded production model. Work spaces know to which activities and construction methods they belong, when, where and for how long they exist and how much volume they occupy. Since a construction schedule consists of number of activities requiring variety of spaces, it is not always possible to specify the time space conflicts corresponding to various workspaces in four dimensions manually. In order to identify time space conflicts, potential loss-of- control events for various construction activities. A GIS-based Methodology is developed and implemented for a case study building
\end{abstract}

Keywords-GIS, WIA (Workspace Identification and Adjustment), SCF (Space Capacity Factor), MCWR (Minimum Comfortable Working Range), SDA (Space Demand for Activity), TSN (Total volume of conflicts between $3 D$ execution Spaces of Activities)

\section{INTRODUCTION}

At the pre-construction stage, a schedule is developed to logically sequence the actions required for the timely completion of the constructed facility. This knowledge takes into account the logical sequence of activities required for the construction, as well as the space needed for the execution of the various activities. The layout of the construction site and the organization of spatial requirements are a critical factor, which should be taken into account during the planning phase. This integrates the planning and analysis of spatial requirements before activities commence. A construction project contains information in several spatial (drawings and blueprints) and non-spatial (schedule, cost estimate, specifications, etc.) data. The overlaps and lack of consistency in information may frequently contribute to the construction errors, which results in miscommunications that are expensive and time-consuming in nature. The planning of space use on the construction site is critical to the successful execution of the schedule of activities.

Construction activities need space on the job site for their implementation. Different activities require different area, different workers, equipments, materials, Temporary Facilities and the structure to be constructed share out a limited space on the jobsite during the construction phase. The mismanagement of activity space requirements throughout planning and scheduling stages results in timespace conflicts in an activity space requirement with another activity's space requirement, this leads to the loss of time and resources. Different activities spaces have different space which varies during the course of the action, which makes exact determination of an activity space unpredictable. The spaces required by different activities change in all three dimensions with time (labourers, equipment, and material). An efficient workspace modelling method is required to amenably and accurately reflect the real workspace.

\section{LITERATURE REVIEW}

Database management capabilities of GIS can be used in construction industry. To extend the use of a GIS based 4D construction management approach for different phases of a construction project, GIS based procedure for quantity take offs, cost estimate and direct sunlight visualization are also developed and integrated with it. Several programmes are developed within GIS to extract necessary dimensions from building model to generate the accurate bill of quantities and cost estimate.

4D planning development is illustrated as accomplished manually. It is proven that the manual procedure adopted in 4D planning simulation presents a lot of difficulty and little productivity. In this way, the $4 \mathrm{D}$ visualization is unviable on the building schedule. Therefore, it is extremely important that it makes a connection between software of planning and graphical visualization, namely Microsoft Project and AutoCAD, respectively. Finally they discussed that is possible to establish a connection between Microsoft Project and AutoCAD, allowing the integration and developing 4D planning, but this methodology needs to be analysed with great care about software development specialists to check about its practical use.

\section{CONSTRUCTION SPACE PLANNING METHOD}

\section{A. Equations}

Geographical Information Systems (GIS) are among the fields of research where computers are of great assistance. With the availability of personal computers, GIS is being used in many areas with a wide range of specialists to solve different problems.

GIS is a computer-based tool used extensively to solve various construction engineering problems involving the use of both spatial and nonspatial information and has 
supplemented the already existing abilities and knowledge in the construction industry. It is a tool for creating, managing, analyzing, and visualizing all types of geographic information. The use of GIS in the construction industry has already been reported for various purposes such as database management, information integration, complex visualization, site layout, construction planning, etc.. Most of the work done so far have used GIS in combination with different softwares to meet various project requirements like scheduling, data managements, construction simulation, etc. The use of GIS has been successful in improving the construction planning and design efficiency by integrating spatial and non-spatial information in a single environment.

\section{B. Equations}

Macro level spaces includes materials storage areas, has received considerable attention. Planning the macro areas for the construction site is of great importance, as errors at this stage could result in constricted access to the site as the building or product evolves. Approaching this problem as a dynamic entity is important as the evolution of the site can have impact on such items as materials storage, construction plant location and site offices. Furthermore, variations in location or dimension of these items over the construction period can have serious impact on the safety on the site.

\section{Micro Space Planning}

Micro level (or work execution) space is the area required within the proximity of the component being installed. This space can also include the building components being installed. Planning of micro level activities are difficult, as they are extremely dynamic and are not fixed in the same position for the duration of the activity.

\section{METHODOLOGY}

\section{A. Case Study}

This case study covers construction of the Hostel Building. The construction of hostel building started in January 2018 with the stipulated period of 24 Months. The hostel building is G+7 with the capacity of 1000 students with all the modern facilities. The dinning hall, kitchen, visitors room, library and common room etc. have been provided in the building. Five staircases have been provided in the building for easy movement. Three lifts have been provided in the building. As per Government norms Ramps have been provided and the washrooms for disabled persons have been provided on each floor.

Being in the research stage, the proposed methodology is implemented on the hostel building. The 2D drawing of the Building is shown in Fig 1\&2. The entire work was divided into scheduling and calculation of workspace respectively and identifying the area of conflicts in there execution to manage the project effectively.

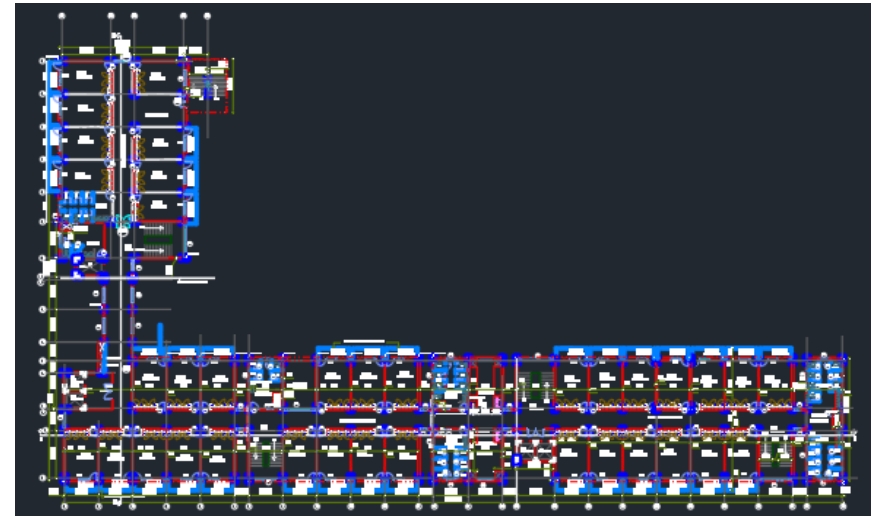

Fig. 1. Plan of Hostel Building

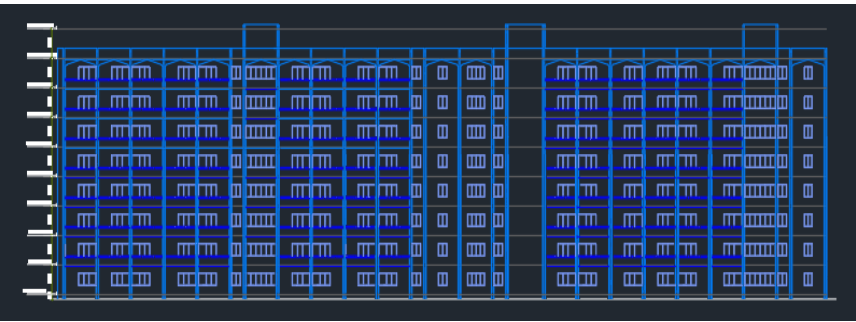

Fig. 2. Front View of Hostel Building

\section{B. Scheduling}

Microsoft project planner was used for scheduling for different components activities. Microsoft Project is a project management software program developed and sold by Microsoft which is designed to assist project managers in developing plans, assigning resources to tasks, tracking progress, managing budgets and analyzing workloads.

\section{Modelling of Building}

GIS based topology was used to integrate the behaviour of different areas to support various types of spatial relationships. The modelling of hostel building is done using Google sketchup and then exporting data into ArcGis.

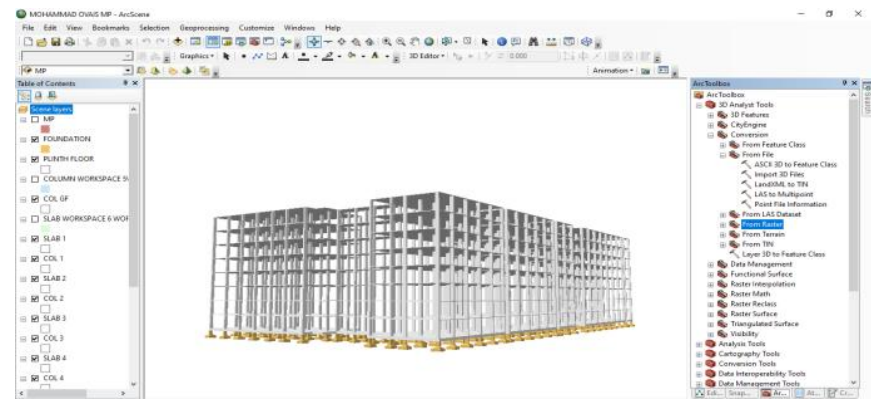

Fig. 3. Modelling of Frame for the Building.

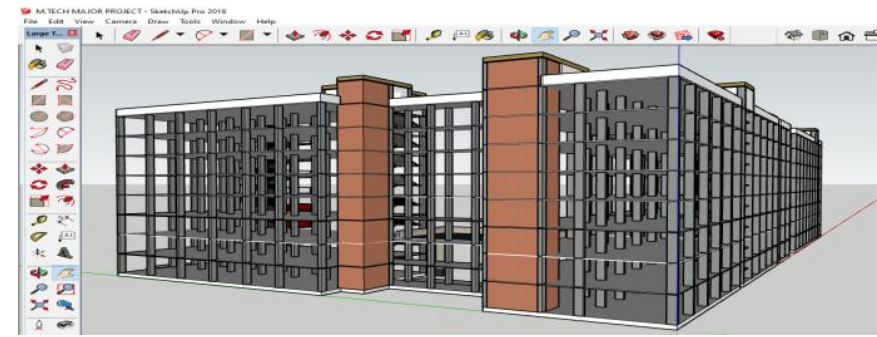

Fig. 4. Modelling of Some Other Components of Building 


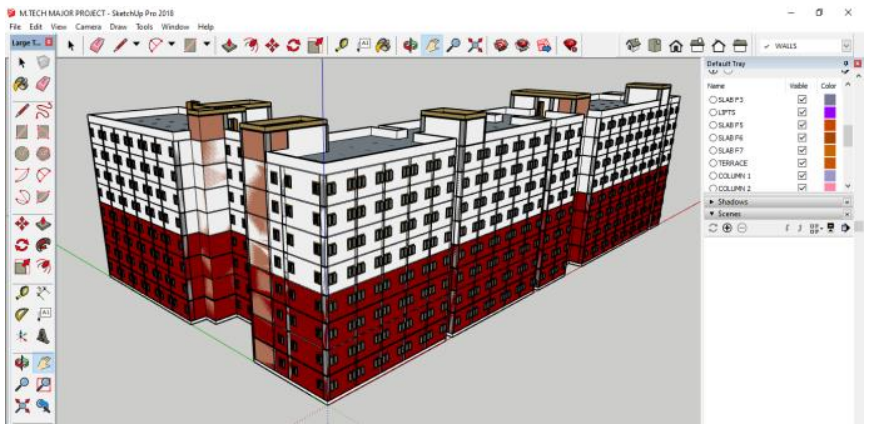

Fig. 5. Building Model in Sketchup

\section{WIA Method}

Using this MCWR system space loaded modelling of hostel building is done mainly for two activities (column and slab). The space requirement for different activities, using equation (1) is done by giving input in the excel work sheet.

Area $\geq 0.9 \times 0.9 \mathrm{~m} \times$ number of workers $\times$ adjust factor (1)

\section{E. Labour Workspace Calculation}

The proposed method uses the equation (1) for creation of workspace which gives a dynamic workspace structure to represent an activity. Basically in this research workspace is generated mainly for 2 activities i.e. columns, slabs. By using default but customizable parameters for workspace creation, further these above mention activities are sub divided, into number of activities of which space requirements changes over time.

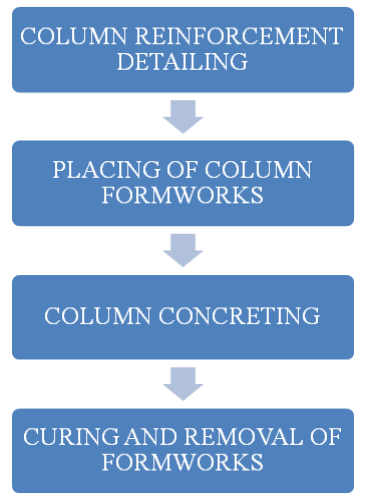

Fig. 6. Space evolution pattern of column activity

Steps Involved in calculating column workspace:

\section{Column Workspace Modelling}

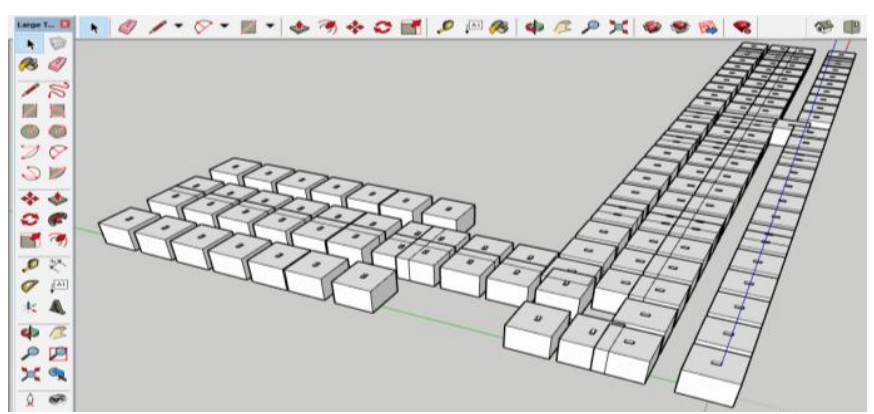

Fig. 7. Workspace required for column concreting
2. Conversion and Exporting Google Sketchup Files to Collada.

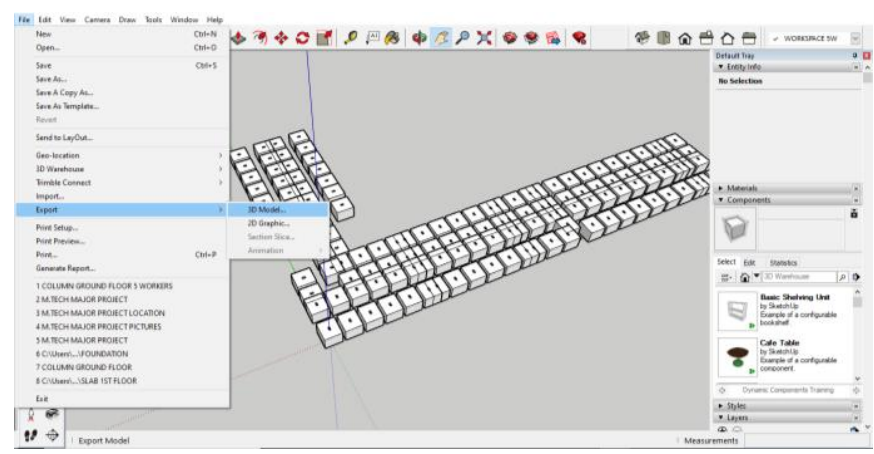

Fig. 8. Exporting workspace component

3. Importing File To Arcscene

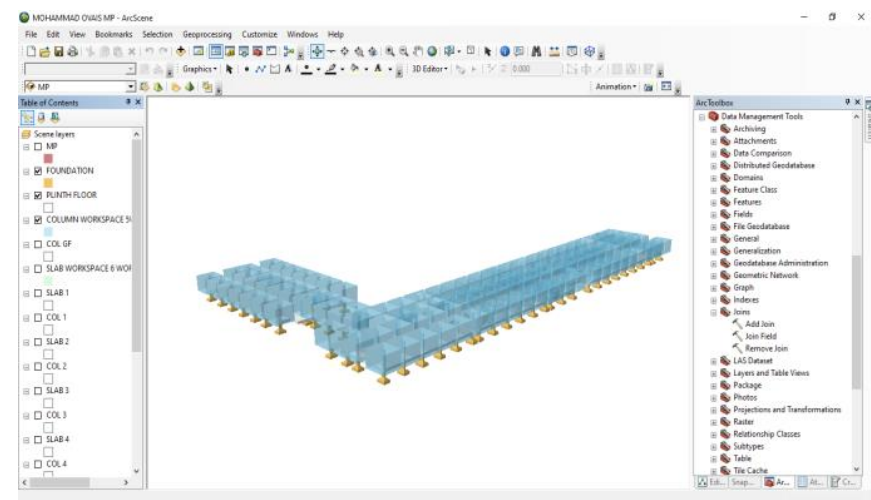

Fig. 9. Importing files into ArcGis

Similar steps should be done for slab members and for all levels and members.

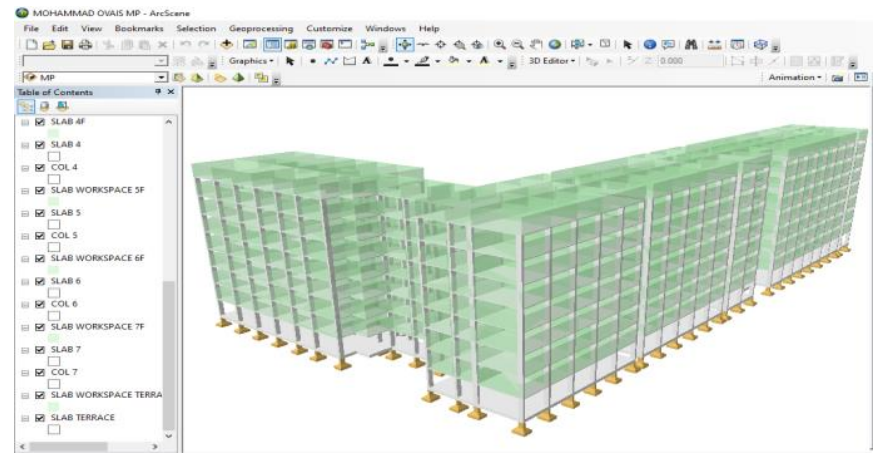

Fig. 10. Complete Space Loaded Model

\section{F. Time Animation}

Various steps involved to evaluate and visualize the construction schedule within ArcsScene are discussed below:

Step 1: Construction Schedule

Step 2: Linking activities with corresponding 3D members.

Step 3: Enabling time layer for each component in ArcGIS

Step 4: Animation construction process 


\section{RESOLUTION OF TIME SPACE CONFLICT}

Since time-space conflicts have multiple types, the analysis of time-space conflicts involves not only the detection of spatial conflicts, but also the categorization of the conflicts.

The methodology uses 3D animation to check time-space conflicts. A space conflict is said to occur when a space during a same time period is demanded by more than one activity. Once a conflict is detected, affected activities are analysis and for conflict resolution, following strategies are used to either resolve or minimize the space conflicts:

1. Adjustments in Space Requirement Strategy used to adjust space demand by changing the locations of conflicting spaces or by changing the originally assigned adjust factor used in equation (1) in order to decrease or increase spaces requirement. In this strategy, the space requirements for different activities are altered to eliminate or minimize the conflicts.

2. Schedule Alteration parallel activities in a schedule sometime lead to site congestion, schedule delay, and unsafe working environment. Therefore, such situations must be avoided by correcting the execution schedule before its implementation. Alternate construction sequences have to be explored by re- sequencing the project activities or by changing the construction methods. This includes changes in interrelationships among activities, duration of space requirements, or splitting activities to resolve conflicts. Activities on the critical path should be given priority for their space demand. Attempts should be made to identify alternate sequences in such a way as to maximize the number of conflicts resolved.

3. Adjustments in Space Requirements and Schedule in this characteristics of each activity participating in a conflict are analysed in detail. This assists planners in deciding which activity's spaces need adjustments and which part of a schedule need alteration. This strategy includes changes in the space requirements and execution schedule at the same time. Changes in space requirements, construction methods, or/and sequence most likely resolve the majority of space conflicts. In sequence alteration process, if activities in a schedule need addition/deletion and editing in the corresponding components' geometry then a revised 4D execution.

\section{CONCLUSION}

This study has provided a prototype system, which could improve space planning on construction projects, and potentially assists in the avoidance of costly time space conflicts. However, throughout the duration of this study, various issues have been identified, which could potentially improve the planning and analysis of space usage during the construction process. The recommendations discussed herein are divided into two categories. The first details potential extensions to underlying research theories developed in this study. The expansion of these theories would provide a more robust technique of planning space usage. The second category is concerned with recommendations for future enhancements to the prototype system developed. Several of these initiatives are interrelated with future enhancements to the underlying space planning recommendations.

\section{REFERENCES}

[1] B. Akinci, M. Fischer, R. Levitt and R. Carlson (2002a) "Formalization and automation of time-space conflic analysis."J. Comput. Civ. Eng., 10.1061/(ASCE)0887 3801(2002)16:2(124), 124-134.

[2] B. Akinci, M. Fischer, R. Levitt and R. Carlson (2002b) "Automated generation of work spaces required by construction activities.”J. Constr. Eng. Manage., 10.1061/(ASCE)07339364(2002)128:4(306), 306-315.

[3] V. K Bansal (2010). "Use of GIS and topology in the identification and resolution of space conflicts". Journal of Computing in Civil Engineering, vol. 25, no. 2, pp. 159-171.

[4] V. K Bansal and M. Pal, (2008). "Generating, evaluating, and visualizing construction schedule with Geographic Information Systems.” J. Comput. Civ. Eng., 22(4). 233-242.

[5] V. K Bansal and M. Pal, (2006). "GIS based projects information system for construction management." Asian J. of Civ. Eng. (Building and Housing), 7(2), 115-124.

[6] K.W. Chau, M. Anson and J. P. Zhang. 2004. "Four-Dimensional visualization of construction scheduling and site utilization". Journal of Construction Engineering and Management. ASCE, 130 (4): 598 606.

[7] N. Dawood, E. Sriprasert and Z. Mallasi. 2003. "Visualisation development: a whole building Task6: VIRCON Technical Report", University of Teesside, Middlesbrough, UK

[8] Sy-Jye Guo and Chun-Ta Wu (2002). "A Decision Support System for Space Conflict Resolution in Building Construction”. Dept. of Civil Engineering, National Taiwan University.

[9] Burcu Akinci, Martin Fischer, John Kunz, Ray Levitt (2000). "Automated Generation of Work Spaces Required by Construction Activities.” CIFE Working Paper \#58.

[10] Kim Jonghoon, Kim Jung-In, Kweon Heeyeon (2006) "Representation of work spaces using a parametric model to support time-space conflicts analysis". Joint International Conference on Computing and Decision Making in Civil and Building Engineering Montréal, Canada.

[11] Samuel João da, S., G. Luis Alberto and J. Antônio Edésio. 2005 "4D planning methodology for integrating planning and graphical visualization softwares". Department of Civil Engineering, Federal University of Santa Catarina, Santa Catarina, Brazil.

[12] David R. Riley and Victor E. Sanvido (1995). "Patterns of Construction-Space Use In Multistorey Buildings". Journal of Construction Engineering and Management, Vol. 121.

[13] Rajiv Chavada, Nashwan Dawood and Mohamad Kassem (2011) "Construction Workspace Management: The Development and Application of a Novel nD Planning Approach and Tool". Journal of Information Technology in Construction (ITcon), Vol. 17, pg. 213 236.

[14] A. Retik, and A. Shapira (1999). "VR based planning of construction site activities." Automation in Construction, 8(6), 671-680.

[15] Akinci, B., Fischer, M., Kunz, J., and Levitt, R. (2002c) "Representing work spaces generically in construction method models." J. Constr. Eng. Manage., 10.1061/(ASCE)07339364(2002)128:4(296), 296-305.

[16] Xing Su and Hubo Cai, M.ASCE (2014). "Life Cycle Approach to Construction Workspace Modelling and Planning". 10.1061/(ASCE)CO.1943-7862.0000855.

[17] Wu, I. and Chiu, Y. (2010). "4D Workspace conflict detection and analysis system". Proceedings of the 10th International Conference on Construction Applications of Virtual Reality, Japan.

[18] P. P. Zouein, and I. D Tommelein. (1993). "Space schedule construction." Computing in civil and building engineering, ASCE, New York, N.Y., 17701777.

[19] B. Koo, and M. Fischer. 2000. "Feasibility study of 4D CAD in commercial construction. Journal of Construction Engineering and Management". ASCE, 126(4): 251-260.

[20] G. Winch and S. North (2006). "Critical space analysis. Journal of Construction Engineering and Management”, vol. 132, no. 5, pp. 473-481. 
[21] K.W Chau, M. Anson and J. P. Zhang. 2004. "Four-Dimensional visualization of construction scheduling and site utilization". Journal of Construction Engineering and Management. ASCE, 130 (4): 598606.

[22] J. Cherneff, R. Logcher, and D Sriram (1991). "Integrating CAD with construction-schedule generation." Journal of Computing in Civil Engineering, 5(1), 64-84.

[23] S. Guo, (2002). "Identification and resolution of work space conflicts in building construction", Journal of Construction Engineering and Management, July/August 2002, Vol. 128, No. 4 pp. 287-29.

[24] G. Howell, A Laufer and G Ballard (1993). "Interaction between subcycles: one key to improved methods." J. COllStr. Engrg. and Mgmt., ASCE, 119(4), 714728. 